\title{
VACINAÇÃO DE PESSOAS FORA DO GRUPO PRIORITÁRIO: UM DESRESPEITO À ÉTICA, À MORAL E ÀS NORMAS LEGAIS
}

\author{
VACCINATION OF PEOPLE OUTSIDE THE PRIORITY GROUP: A DISRESPECT TO ETHICS, \\ MORALS AND LEGAL STANDARDS
}

Carmen Stephany Gomes Freire

Universidade Federal de Roraima, Boa Vista, RR, Brasil. E-mail: csgomesfreire16@gmail.com

\section{Merian Pereira da Silva}

Universidade Federal de Roraima, Boa Vista, RR, Brasil. E-mail: meryanrr@gmail.com

\section{Nataliene Cavalcante Rodrigues}

Universidade Federal de Roraima, Boa Vista, RR, Brasil. E-mail: nataliene_cavalcante@outlook.com

\section{Douglas Verbicaro Soares}

Universidade Federal de Roraima, Boa Vista, RR, Brasil. E-mail: douglas_verbicaro@yahoo.com.br

DOI: https://doi.org/10.46550/amormundi.v2i4.116

Recebido em: 02.08.2021

Aceito em: 07.09.2021

\begin{abstract}
Resumo: O presente artigo discute a complexidade da pandemia, analisando as questóes em torno das campanhas de vacinação contra a COVID-19, a entrega da vacina, o público-alvo, e as complicaçôes decorrentes dos casos de denúncias de fraudes. Todas essas abordagens tomando como exemplificação os casos ocorridos na cidade de Sabará/MG, onde profissionais, fora da linha de frente, estavam sendo imunizados antes dos grupos prioritários. Por fim, o estudo fará uma correlaçấo com o ponto de vista da ética em relaçáo a essas condutas e impactos sociais. Para o estudo foi pensada uma abordagem bibliográfica multidisciplinar. Nesse sentido, conclui-se que a falta de diretrizes claras para a vacinação acarretou uma série de problemas ao poder público e à sociedade em geral.
\end{abstract}

Palavras-chave: Pandemia. Solidariedade. Crise.

Abstract: This article discusses the complexity of the pandemic, analyzing the issues surrounding vaccination campaigns against COVID-19, the delivery of the vaccine, the target audience, and the complications arising from cases of fraud complaints. All these approaches taking as an example the cases that occurred in the city of Sabaral/MG, where professionals, outside the front line, were being immunized before priority groups. Finally, the study will make a correlation with the point of view of ethics in relation to these behaviors and social impacts. For the study, a multidisciplinary bibliographic approach was designed. In this sense, it is concluded that the lack of clear guidelines for vaccination has caused several problems for the public authorities and society in general.

Keywords: Pandemic. Solidarity. Crisis. 


\section{Introduçáo}

$A_{\text {pessoas que náo se encaixam nas condiçóes estabelecidas pelas organizaçóes de }}^{\text {ssim }}$ referência em saúde como prioridade na vacinação, que têm sido imunizadas. As vacinas criadas recentemente para combater a Covid-19 podem ser consideradas um bem escasso, principalmente, devido a demanda global e de certa forma na ausência de insumos para a produçáo em grande escala, mesmo que existam diferentes tipos de imunizantes.

Por isso, assim como em outros países ao redor do mundo, no Brasil buscou-se a vacinação dos chamados grupos prioritários: que são aquelas pessoas mais vulneráveis que, consequentemente, podem desenvolver casos mais graves da doença e, também, aquelas que trabalham na linha de frente de combate contra o vírus. No entanto, quando se iniciou a imunização contra o novo coronavírus, observou-se muitas pessoas que não se encaixam nas condiçóes estabelecidas pelas organizações de referência em saúde como prioridade estavam sendo imunizadas.

Os casos ocorridos no Brasil, trouxeram grande notoriedade ao assunto em questão, em especial o qual será abordado neste trabalho, em cidades do estado de Minas Gerais, onde além de idosos e profissionais de saúde, pessoas como professores de educação física e veterinários estariam sendo vacinados mesmo não estando no combate direto contra o vírus. Além disso, tais pessoas estariam publicando fotos em redes sociais agradecendo a imunizaçáo.

Não foi um caso isolado desse estado, em outros estados do país pessoas que não se encaixam nos grupos de risco estariam se vacinando. Após denúncias de fraudes na ordem de vacinação, promotores de justiça e procuradores de diferentes regiōes, decidindo instaurar procedimentos investigativos. Segundo levantamento realizado pela Agência Brasil, em janeiro de 2021, pelo menos em 10 Estados, mais o Distrito Federal havia denúncias de irregularidades e por causa disso o MPE - Ministério Público do Estado destas regiōes explicitadas e o MPF Ministério Público Federal estariam solicitando explicaçóes dos agentes políticos e responsáveis (AGÊNCIA, 2021, p. 1).

Diante desses fatos, surgiram diversos questionamentos relevantes a respeito da definição de como cada ente governamental, em especial de como os municípios deveriam agir. Para que, seguindo a plano nacional de imunização, pudessem definir os grupos prioritários. Dessa forma, vindo a fazer uma distribuição mais ética e justa da vacina para a população.

Como expóe-se no decorrer deste estudo, a ordem de vacinação é ferramenta para atender pessoas realmente necessitadas neste início de imunização, e envolve, igualmente, uma questáo de ética e justiça, assim como solidariedade da própria população neste momento de crise sanitária.

Para tal pesquisa, realizou-se uma revisão por meio de levantamentos de periódicos científicos indexados em sites que tratavam sobre a COVID-19, os aspectos correspondentes a esta doença e questóes que acabara surgindo acerca de fraudes e os "fura-fila". Os seguintes descritores, em língua inglesa, foram considerados: "COVID-19" e "SARS-CoV-2". Os artigos incluídos no estudo foram publicados entre janeiro e julho de 2020, selecionados de acordo com o seu grau de relevância para a proposta dessa revisão. Em seguida, os dados foram sistematizados em quatro categorias buscando responder as seguintes perguntas: Quais os principais impactos sociais causados pela pandemia? Quais as políticas de imunização foram adotadas para o combate 
ao Coronavírus? Como pode ser aplicada a ética em face a saúde e as políticas de imunização? E quais os crimes previstos em lei relacionados ao ato de "furar fila"?

\section{A pandemia e os impactos sociais}

A Pandemia do novo coronavírus ou COVID-19 - SARS-CoV-2 (OPAS, 2021), vem produzindo repercussôes não apenas de ordem epidemiológica, mas também, repercussóes e impactos sociais, econômicos, políticos, culturais e históricos. Nesse cenário, o meio mais viável para se obter um possível equilíbrio, em meio a instalada crise sanitária, seria a produção de imunizantes contra a doença.

Em linhas gerais, por causa da escassez de vacinas, o Ministério da Saúde definiu uma série de critérios para priorizar e dividir os grupos mais vulneráveis ao contágio pelo coronavírus, tendo que implantar um plano que se ocasiona as medidas necessárias para o enfrentamento, com o intuito de alcançar uma possível solução.

Devido à necessidade quanto à definição e priorização dos grupos a serem vacinados, foi elaborado o Programa Nacional de Imunização, tendo como grupos prioritários profissionais de saúde, idosos e populaçôes tradicionais - os critérios são níveis de exposição e risco diante da doença. Os profissionais de saúde, por estarem na linha de frente do cuidado dos pacientes com COVID-19, foram os primeiros a serem vacinados. Outros grupos serão incluídos na estratégia de vacinação na medida em que houver disponibilidade de vacinas como os professores, entre outros trabalhadores considerados como essenciais. Contudo, os Estados possuem autonomia para fazer a distribuição das vacinas e definir suas prioridades, com base nas recomendaçóes.

Apesar de todo um estudo e planejamento para a distribuição das vacinas, há diversos casos de pessoas que não fazem parte do grupo prioritário para a vacinação, mas que mesmo assim foram imunizadas, casos esses que acabaram se tornando alvos de investigaçóes. Os diversos casos de "fura-filas" pelo país seguem sendo denunciados aos Ministérios Públicos, e havendo a comprovação de ilegalidade, os envolvidos poderão sofrer puniçóes.

\section{Do surgimento do novo Coronavírus e a política de imunização}

No final de 2019 surgiu em Wuhan, na China, uma nova doença que passou a assolar o mundo: a Covid-19, que é uma infecção respiratória aguda causada pelo novo coronavírus (SARS-CoV-2). É uma doença potencialmente grave, de elevada transmissão e de distribuição sendo caracterizado em março de 2020 como uma pandemia (BRASÍLIA, 2020, p.14).

Segundo o Escritório Regional para as Américas da Organização Mundial da Saúde, uma em cada seis pessoas fica gravemente doente e com dificuldades respiratórias, sendo que pessoas idosas e com morbidades tem maiores riscos de desenvolver sintomas graves da doença ou até mesmo chegar a óbito (OPAS, 2021).

Nesse cenário, o número de mortes foi cada vez mais crescendo ao redor do mundo, chegando a mais triste marca de 2 milhóes de mortes no mundo em abril de 2021, segundo o site oficial da ONU (ONU NEWS, 2021, p. 1). Após cerca de um ano da chegada do vírus ao Brasil, mais de 250 mil pessoas haviam perdido a vida para a doença, tornando-se o segundo país no mundo com mais morte por Covid-19 no mundo, atrás apenas do Estados Unidos da América 
(BRAZILIENSE, 2021, p. 1), fato este que ressalta as consequências tristes desta doença.

Diversas medidas foram tomadas desde o início da pandemia para conter a disseminação do vírus, desde: o distanciamento social, o uso de máscaras, até determinaçóes mais sérias como toque de recolher e lockdown. Iniciou-se ainda, uma corrida para o desenvolvimento de vacinas contra o vírus em todo mundo, buscando uma vacina que com eficácia e segurança seria decisiva para a oportunidade de controle da pandemia.

Em 18 de setembro de 1973, foi criado o Programa Nacional de Imunização que tem como finalidade gerir a política nacional de imunização contra doenças e proteção da saúde da população. O programa nacional de imunização demonstrou-se aos longos dos anos bemsucedido e recebeu o reconhecimento da sociedade brasileira e referência em vários países ao redor do mundo (JUNIOR, 2013, p. 07). Seguindo este programa, o Mistério da Saúde, apresentou o Plano Nacional de Operacionalização da Vacinação contra a covid-19, como medida para controlar o novo coronavírus. Conforme a lei 6.360/1976, o licenciamento das vacinas no Brasil é da atribuição da Agência Nacional de Vigilância Sanitária (ANVISA, 2020, p. 1), e o plano de vacinação é realizado de acordo com esse licenciamento e registro e outros regulamentos técnicos.

Em 2021, algumas vacinas começaram a serem aprovadas para uso no país, iniciou-se então, mesmo que a princípio de forma um pouco lenta, a vacinação da população. É de relevante destaque, porém, que algumas pessoas da população, infelizmente, desenvolvem sintomas mais graves da doença ou mesmo chegam a óbito. Nesse sentido, entre esses fatores contribuem para o agravamento dos casos: características próprias do indivíduo, como doenças pré-existentes ou pessoas com elevada vulnerabilidade social.

Considerando tais aspectos, o Plano Nacional de Operacionalização da Vacinação Contra a Covid-19 definiu estratégias para a ordem de vacinação, definindo grupos prioritários de acordo com a quantidade disponível de doses e critérios estabelecidos pela OMS, especificando que faria parte:

Optou-se pela seguinte ordem de priorização: preservação do funcionamento dos serviços de saúde, proteção dos indivíduos com maior risco de desenvolvimento de formas graves e óbitos, seguido da preservação do funcionamento dos serviços essenciais e proteção dos indivíduos com maior risco de infecção (BRASILIA, 2020, p. 26).

Cumpre destacar, ainda que, o objetivo principal no combate à Pandemia vem sendo a vacinação de, pelo menos, a maioria da população. Desse modo, com o passar do tempo, esperase que a distribuição e aplicação de vacinas tenda a expandir para outros grupos, chegando a vacinar pessoas que, a este tempo, não ação consideradas grupos prioritários. Isso é consequência inevitável, em razão do provável aumento da produção de vacinas, bem como o desenvolvimento de novos imunizantes por diversos países, sendo estas aprovadas pelos órgãos governamentais responsáveis para uso emergencial no Brasil.

4 A ética aplicada a saúde pública e as vacinas da Covid-19 e os crimes previstos em lei relacionados ao ato de "furar fila"

Pode-se definir a ética como aquela que segue preceitos do se é considerado certo e errado dentro de uma sociedade, então, é possível encontrá-la em qualquer campo que abranja uma sociedade. Assim, na área de saúde não poderia ser diferente. Desta forma, a ética aplicada à 
saúde comunitária, seria uma avaliação, dos métodos e riscos, como também, a devida atenção às atividades que devem promover o bem-estar dos pacientes. Contudo, no presente caso em análise, póe-se em prova a ética e a moral, não apenas das pessoas que estão tomando a vacina, mesmo náo pertencendo à linha de frente ou ao grupo de risco, mas também, dos profissionais que concordaram com tal atitude tomada.

Como já explicado, o Plano Nacional de Operacionalização da Vacinação Contra a Covid-19, já havia estabelecido os critérios para aqueles que deveriam ser prioritariamente vacinados. De fato, os profissionais educadores físicos também estão incluídos no plano nacional como profissional de saúde, porém, estes não estão atuando na linha de frente, e majoritariamente, não são enquadrados dentro do grupo de risco (BRASILIA, 2021). Portanto, a princípio, não poderiam ser enquadrados como profissionais de prioridades, de forma que ao vacinarem essas pessoas que trabalham com: educação física e, no mesmo sentido os veterinários, os questionamentos sociais surgiram para criticar a prefeitura da cidade de Sambará/MG em uma suposta prática antiética.

É válido destacar que as vacinas são um produto que pode ser considerado essencial para a vida no atual cenário vivido, porém é escasso. Pode-se dizer que, em algum momento, os professores de educação física e médicos veterinários seriam vacinados, mas o fator questionado socialmente se deu ao fato de que a vacinação antecipada destes profissionais teria impactado na imunização imediata de pessoas que apresentam maior riscos de contrair o vírus. Nessa conjuntura, vacinar os profissionais de educação física ou médicos veterinários poderia constituir algum tipo de prática antiética?

O professor de direito da UFMG, Marcelo Campos Galuppo em seu podcast Sapientia no episódio intitulado "as vacinas e a ética" e no artigo de "[Opinião] Vacinas privadas na crise: ciência e ética", afirma que:

Ainda que nós como cidadãos coloquemos limites éticos aos usos e aos métodos da ciência, a ciência não se pauta por critérios éticos, a ética chega à ciência de fora e não a partir de si própria, porque a lógica da ciência é a causalidade mecânica, que exclui a valoração de fins, e ainda que os membros do comitê científico possam elencar razóes éticas para estabelecer uma ordem de prioridade, o que importa no fundo, sáo as consequências causais de uma determinada açáo (GALUPPO, 2021).

Portanto, as consequências causais relacionadas estão ligadas ao fato de que: mais de $60 \%$ das pessoas internadas nas UTIs são pertencentes aos grupos prioritários e a sua imunização, consequentemente, representará uma desopressão nos sistemas de saúde do país. Assim, estes poderão atender com mais eficiência dos pacientes de COVID19 (GALUPPO, 2021). Destarte, segundo essa postura, se poderia concluir positivamente que a vacinação de pessoas fora dos grupos prioritários, possuiria uma repercussão de extrema importância, atribuindo a esta atitude antiética, náo apenas para com os pacientes do grupo de risco, mas para com a sociedade no geral.

É evidente que a vacinação de pessoas fora dos grupos prioritários é um ato imoral e antiético, contudo, não se restringe apenas a isto, gerando uma série de violaçóes ao Ordenamento Jurídico brasileiro, podendo as punições normativas ser aplicadas tanto para aqueles que aplicam as vacinas, como também, aos que recebem de modo antecipado, fora das especificaçóes de grupos prioritários determinados pelos órgãos de saúde do país. 
As condutas podem ser penalizadas por ofenderem os princípios e valores fundamentais da conduta ética, além de ferir o princípio da dignidade humana, contemplado na Constituição Federal de 1988, e em específico, os preceitos previstos no próprio Código de Conduta Ética do Agente Público e da Alta Administração Estadual do Estado de Minas Gerais com o Decreto n ${ }^{\circ}$ 46.644/2014 (MINAS GERAIS, 2014).

Ademais, a banalização da ordem prioritária estabelecida para a vacinação, também, é passível de responsabilização administrativa visto que, como destacado no Estatuto dos Servidores Públicos Civis do Estado de Minas Gerais, Lei n 869/1952, nos artigos 217, inciso IV e 246, inciso I, sendo passível de aplicação da pena de suspensão de até 90 dias por se tratar de falta grave, a referida responsabilização é prevista nestes termos:

Art. 217 - Ao funcionário é proibido: (...) IV - Valer-se do cargo para lograr proveito pessoal em detrimento da dignidade da função; [...]

Art. 246 - A pena de suspensão será aplicada em casos de: I - Falta grave (MINAS GERAIS,1946).

Além disso, tais condutas também podem ser tipificadas como crime pelo Código Penal brasileiro, a depender da denúncia feita, podendo ser enquadrado em delitos de peculato, previsto no art. 312, falsidade ideológica previsto no art. 299, infração à medida sanitária preventiva prevista no art. 268 (BRASIL, 1940), dentre outros crimes tipificados em lei.

Por fim, é adequado afirmar que com o crescente número de denúncias de casos que vêm ocorrendo em diversas partes do Brasil, há uma expectativa da aprovação de projetos de lei específicos para a situação em que o país se encontra no momento, visando assim, a maior proteçấo aos direitos e deveres relacionados de cada ente governamental e indivíduo quanto a vacinação contra o COVID-19.

\section{Consideraçóes finais}

Desta forma, é indispensável frisar que pela análise breve, porém não exaustiva deste estudo, buscou-se abordar a complexidade da Pandemia e as dimensôes no seu enfrentamento, especificamente, a existência das vacinas contra o SARS-CoV-2 à disposição para a população, levando-se em conta as questôes associadas às supostas fraudes que vêm ocorrendo e, desse modo, gerando grande especulaçóes sociais.

Nesse sentido, é de extrema relevância a definição de uma estratégia de comunicação eficiente para esclarecer os motivos de determinado grupo ser vacinado e outro não, ou mesmo entre os grupos priorizados, porque a vacinação deverá ocorrer em etapas.

Advertindo-se, ainda, que a vacinação é de fundamental importância para o enfrentamento desta pandemia que trouxe à tona, repercussôes não apenas de ordem biomédica e epidemiológica, mas também, repercussóes e impactos sociais, econômicos, políticos, culturais e históricos. Até o momento, os resultados das pesquisas mais avançadas mostram a capacidade imunizante de maneira promissora - sobretudo na prevenção de quadros clínicos graves, que atuam fortemente sobrecarregando os sistemas de saúde e, muitas vezes, vitimam os acometidos pelo vírus.

Contudo, apesar de todo o benefício que irá aparecer pela introdução da vacinação contra a Covid-19, ainda é necessário o desempenho com as regras propostas pelo plano de saúde que devem ser seguidas. Nessa questão, visa-se também a orientação, fiscalização e a responsabilidade 
dos governantes. Portanto, é de grande importância a valorização das condutas a partir dos princípios morais, da ética e quando necessário da própria norma jurídica.

\section{Referências}

AGÊNCIA. BRASIL. 22/01/2021. MP apura fura-fila de vacina em ao menos 10 estados e no DF. Disponível em: <https://agenciabrasil.ebc.com.br/saude/noticia/2021-01/mp-apura-furafila-devacina-em-ao-menos-10-estados-e-no-df>. Acesso em: 15 de junho de 2021.

ANCHOR. As vacinas e a ética. Disponível em: <https://anchor.fm/marcelo-campos-galuppo/ support>. Acesso em: 17 de julho de 2021.

BRASIL. Ministério da Saúde. Sobre a doença. O que é COVID-19, 2020a. Disponível em: $<$ https://coronavirus.saude.gov.br/sobre-a-doenca\#o-que-e-covid>. Acesso em: 20 de julho de 2021.

BRASIL. Ministério da Saúde. Plano Nacional de Operacionalização da Vacina contra a Covid-19. Disponível em: <https:/www.gov.br/saude/pt-br/media/pdf/2020/ dezembro/16/ plano_vacinacao_versao_eletronica-1.pdf>. Acesso em: 06 de julho de 2021.

BRASIL. Decreto-Lei 2.848, de 07 de dezembro de 1940. Código Penal. Diário Oficial da União, Rio de Janeiro, 31 dez. 1940. Disponível em: <DEL2848compilado (planalto.gov.br)>. Acesso em: 06 de julho de 2021.

CONSELHO DE ÉTICA PÚBLICA. O que pode acontecer com quem furar a fila da vacina? Disponível em: <https://www.conselhodeetica.mg.gov.br/noticias-artigos/754-o-que-podeacontecer-com-quem-furar-a-fila-davacina\#: : :text=Al\%C3\%A9m\%20de\%20ofender $\% 20$ os $\% 20$ princ $\%$ C3\%ADpios,proveito $\% 20$ pessoal $\% 20 \mathrm{em} \% 20$ detrimento $\% 20$ da> . Acesso em: 19 de julho de 2021.

CORREIO BRAZILIENSE. Um ano de covid-19 no Brasil: país é o $2^{\circ}$ com mais mortes no mundo. Disponível em: <https://www.correiobraziliense.com.br/brasil/2021/02/4 908968um-ano-de-covid-19-no-brasil-pais-e-o-2-com-mais-mortes-no-mundo.html>. Acesso em: 21 de julho de 2021.

FACULDADE IDE. Ética na saúde: quais as condutas essenciais de um profissional? Disponível em: <https://www.faculdadeide.edu.br/blog/etica-na-saude-quais-ascondutas-essenciais-de-umprofissional/>. Acesso em: 17 de julho de 2021.

GALUPPO, Marcelo Campos. [Opiniāo] Vacinas privadas na crise: ciência e ética. UFMG. Disponível em: https://ufmg.br/comunicacao/noticias/opiniao-imunizacao-privada-na-criseciencia-e-etica. Acesso em: abril de 2021

MINAS GERAIS. Decreto No 46.644, de 6 de novembro de 2014. Dispóe sobre o Código de Conduta Ética do Agente Público e da Alta Administração Estadual. Minas Gerais Diário Do Executivo - 07/11/2014 PÁG. 1 COL. 1. Disponível em: https://www.almg.gov.br/ consulte $/$ legislacao $/$ completa/completa.html?tipo=DEC\&num $=46644 \& a n o=2014 \& a b a=j s$ textoOriginal. Acesso em: abril de 2021.

MINAS GERAIS. Lei No 869 de 05 de julho de 1952. Dispóe Sobre O Estatuto Dos Funcionários Públicos Civis Do Estado De Minas Gerais. Disponível em: https://www.almg.gov. 
br/consulte/legislacao/completa/completa-nova-min.html?tipo=LEI \&num =869\&ano=1952. Acesso em: julho de 2021.

ONU NEWS. Mundo chega a 2 milhöes de mortos por Covid-19. Disponível em: <https://news. un.org/pt/story/2021/01/1738882\#:-:text=BR\&text=Neste $\% 2015 \% 20 \mathrm{de} \% 20 \mathrm{j}$ aneiro $\% 20$ de, impressionante $\% 20$ est $\% \mathrm{C} 3 \% \mathrm{~A} 3 \mathrm{o} \% 20$ nomes $\% 20 \mathrm{e} \% 20$ rostos> . Acesso em: 21 de julho de 2021.

OPAS/OMS BRASIL. Folha informativa COVID-19 - Escritório da OPAS e da OMS no Brasil. Escritório Regional para as Américas da Organização Mundial da Saúde Organização PanAmericana da Saúde. Disponível em: <https://www.paho.org/pt/covid19>. Acesso em: 19 de julho de 2021.

SILVA JUNIOR, Jarbas Barbosa da. 40 anos do Programa Nacional de Imunizaçôes: uma conquista da Saúde Pública brasileira. Epidemiologia e Serviços de Saúde, v. 22, n. 1, p. 7-8, 2013.

VILAÇA, Vladimir. In: Portal G1. 12/02/2021. Mesmo com poucas doses, prefeituras da Grande BH vacinam pessoas fora da linha de frente. Disponível em: <https://g1.globo.com/ $\mathrm{mg} / \mathrm{minasgerais/noticia/2021/02/12/mesmo-com-poucas-doses-prefeituras-da-grande-bh-}$ vacinampesso as-fora-da-linha-de-frente.ghtml>. Acesso em: 19 de julho de 2021. 